\title{
Kapok as an Adsorbent for Industrial Wastewater
}

\author{
Alief Uzair Naharudin, Siti Hajar Noor Shaarani", Lim Mei Rou, Nor Hanimah Hamidi, Noormazlinah Ahmad and Ruwaida Abdul \\ Rasid \\ Faculty of Chemical and Process Engineering Technology, Universiti Malaysia Pahang, Lebuhraya Tun razak, 26300 Gambang, Pahang, Malaysia.
}

\begin{abstract}
The study focuses on investigating kapok fiber as an adsorbent for oily industrial wastewater. Kapok fiber, KF (Ceiba Pentandra) is a natural plant fiber that poses excellent hydrophobic-oleophilic characteristics, due to the presence of penetrable hollow lumen structure and waxy material on its surface. The objectives of this study are to investigate the morphology of raw and treated kapok fiber (KF) before and after adsorption of wastewater as well as to study the sorption capacity of KF (including raw KF, ethanol-treated KF and chloroform-treated KF) in wastewater. Hence, the morphology of raw KF and KF treated with oil are analysed using scanning electron microscopy (SEM). Besides, the sorption condition of different types of wastewater including emulsified wastewater, immiscible oil-and-liquid wastewater and non-oily wastewater on raw KF are studied in this experiment. From the study, the raw KF shows the best sorption capacity of oil $(29.00 \mathrm{~g} / \mathrm{g})$ compared to the ethanol-treated KF $(18.22 \mathrm{~g} / \mathrm{g})$ and Chloroform-treated KF $(16.58 \mathrm{~g} / \mathrm{g})$ as the treated KF has larger amount of cellulosic content (hydroxyl group) present on the wall of kapok, making it less oleophilic. On the other hand, raw KF has the lowest sorption capacity of water $(0.59 \mathrm{~g} / \mathrm{g})$ followed by ethanol-treated KF $(3.05 \mathrm{~g} / \mathrm{g})$ and chloroform-treated KF $(3.20 \mathrm{~g} / \mathrm{g})$ on non-oily wastewater. Kapok fiber shows great potential as oil sorbent on any type of oil owing to its excellent hydrophobicity-oleophilicity characteristic. In conclusion, the raw KF shows the best sorption capacity of oil compared to the ethanol-treated KF and chloroform-treated KF because the effectiveness is resulted from the hydrophobic waxy coating on the kapok surface. Besides that, the lower sorption capacity of water than oil is due to the incomplete removal of wax from the wall of kapok, making it a little hydrophilic (likes water) as compared to oleophilic (likes oil).
\end{abstract}

KEYWORDS

kapok fiber,

hydrophobic-oleophilic, adsorbent,

wastewater,

pre-treatment,

sorption capacity.

\section{INTRODUCTION}

Water preservation implies on recovering oil and hydrocarbon oil from water, among other pollutants such as dye and heavy metals. Among the main existing techniques, the use of a sorbent seems to be interesting because its function is to induce separation of oil and water so that the oil can easily be recovered (Idris et al., 2014). In this aim, the sorbent should have a high oleophilic and hydrophobic property. The sorption capacity is measured by the liquid sorption ratio (Deschamps et al., 2013). It is desired if the sorbent has the capability of drawing the oil into the material matrix, which implies a porous structure. Besides, the faster the oil is trapped, the less likely it will disperse and get away, and the easier the recovering operation will be (Deschamps et al., 2013). The sorbent's buoyancy and durability in aqueous media should be high as it should not retain water and react like a hydrophilic product. Its retention capability should also be high, so that the adsorbed oil should not drain too quickly. It should rather be reusable, nontoxic for the environment if not reused, and preferably biodegradable (Deschamps et al., 2003). It has been proven that the adsorbents have a significant capacity for oil uptake from the water surface to reduce the treatment costs and minimize harmful effects on ecosystems (Venkates and Rao, 2006). In recent years, kapok fiber has received increasing attention as an oil-absorptive material due to its distinct hollow structure and hydrophobic characteristics (Lim and Huang, 2007; Hori et al., 2000; Abdullah et al., 2010; Huang and Lim, 2006). In these studies, kapok fiber exhibited good water repellence, high oil adsorption capability, and well reusable characteristics, demonstrating its potential as an alternative for application in oil pollution control.

The treatment of wastewater can be carried out by various techniques. Most of the conventional treatment techniques are rather expensive. Though commercial activated carbon is an ideal adsorbent for the removal of dyes or oil from effluent, it is uneconomical due to its high production cost and regeneration costs (Baseri et al., 2012). At this point, there is a need to develop low cost and effective adsorbent that can treat the wastewater. In recent years, many researchers have focused on development of smart materials with easy handling, lower cost, light weight, and biocompatibility. A variety of lignocellulosic fibers have been studied including the pseudostem of the banana plant, sugarcane bagasse, sponge guard fibers (Guimarães et al., 2009), corn stalk, rice husk, sorghum straw, wheat straw (Varhegyi et al., 2011), coconut fiber 
(Rosa et al., 2010), and sesame husk (Bindu et al., 2011) for various applications. Generally cellulose is utilized as material for polymer composites in various applications such as a drug delivery system (Ge et al., 2010) as well as a flexible humidity and temperature sensor (Mahadeva et al. 2010). Besides, natural fibers can also be applied as a source for renewable energy (Panwar et al., 2011) and biofuels (Pirani and Hashaikeh 2012).

Ceiba pentandra or locally known as kekabu or kapok, is cultivated in Southeast Asia, Malaysia, Sri Lanka, other parts of East Asia and Africa. The fibers are lustrous, yellowish-brown in colour, light, inelastic and brittle. In Malaysia, kapok fiber has been used mainly as a stuffing material for beds and pillows. It is not seasonal, hence kapok is available throughout the whole year. Kapok fiber is a highly lignified organic seed fiber and mainly consists of cellulose, lignin and xylan (Gao et al., 2012). Kapok fiber has many advantages such as: abundant in nature, inexhaustible, low cost, easy processing, renewable, biodegradable, and biocompatible (Mahadeva et al., 2010). The wax layer on the surface of kapok enables this fiber to show excellent hydrophobic-oleophilic characteristics, and accordingly, this fiber is receiving increasing interest as an oil-absorbing material (Zhang et al., 2016). However, the large lumen and waxy surface are not favourable for the access of hydrophilic substances. To enhance the intrinsic properties or alter the surface characteristics, kapok fiber can be subjected to surface modification including chemical treatment, such as alkali/acid treatment, solvent treatment, oxidation treatment and acetyl treatment; and physical treatment, such as ultrasonic treatment and radiation treatment (Zheng et al., 2015). The interfacial properties can be improved by appropriate treatment of the kapok fiber, which gives rise to changes in physical and chemical interactions at the interface.

The raw kapok fibers were contacted with different types of wastewater, including emulsified wastewater, immiscible oil-and-liquid wastewater and non-oily wastewater to study the sorption condition of kapok fiber on industrial wastewater. On the other hand, the sorption capacity of raw and treated kapok on wastewater were studied by performing the adsorption test on cooking oil and dye wastewater.

\section{MATERIALS AND METHODS}

\section{Materials}

Kapok fiber (KF) was separated from the seed pod by bare hand and used as received. KF is lignocellulosic with hydrophobic waxy coating. The raw KF was treated with ethanol and chloroform respectively to obtain ethanol-treated KF and chloroform-treated KF (Lim and Huang, 2007). Chloroform treatment and ethanol treatment were carried out to remove the kapok fibers' waxy surface. After the sample was collected, a preliminary test of KF on wastewater was conducted to determine the effect of KF on emulsified wastewater, immiscible oil-and-liquid wastewater and non-oily wastewater. The pre-treatment of KF was obtained by it soaking in the respective solvent in a glass beaker for one hour then rinsed three times with water and then oven dried overnight to evaporate the residual liquids. The morphology of KF was also studied. Furthermore, the sorption capacity of raw KF, ethanol-treated KF and chloroform-treated KF on oily and non-oily wastewater were obtained by weighing the initial and final weight of samples.

\section{Preliminary test of different wastewater on raw kapok fiber}

Preliminary test of raw KF on wastewater was performed to study the sorption condition of KF on different wastewater. The raw KF (1g) was used as adsorbent in $200 \mathrm{ml}$ of emulsified wastewater, immiscible oil-and-liquid wastewater and non-oily wastewater respectively for 30 minutes. Then, the sorption condition of each wastewater on raw Kapok was studied and recorded.

\section{Analysis of kapok fiber}

The fiber's structure before and after adsorption were analysed by microscopic observation. Kapok morphology was observed by Scanning Electron Microscopy (SEM), a Dual Target Sequential Sputtering System (Q300T D). For SEM analyses, the samples were mounted on round stainless-steel sample holders. The samples were sputter-coated with gold using a sputter coater to provide conductive coating that enhanced the images under SEM. SEM images were examined using accelerating voltage at $5 \mathrm{kV}$.

\section{Sorption capacity of raw and treated kapok fiber on wastewater}

The sorption capacity of different kapok fiber (KF) in wastewater treatment was studied by using $1 \mathrm{~g}$ of raw KF, ethanol-treated KF and chloroform-treated KF as adsorbent in $500 \mathrm{ml}$ of oily solution. The solution was prepared by mixing $200 \mathrm{ml}$ of cooking oil and $300 \mathrm{ml}$ of water at a ratio of $2: 3$. The same steps were repeated by replacing cooking oil with palm oil, crude oil and dye as emulsified wastewater, immiscible oil-and-liquid wastewater and non-oily wastewater respectively. The weight of KF before and after treatment were recorded. The adsorbent was immersed into water for a constant time of 30 minutes. The sorption capacity can be obtained by the following formula (Wang et al., 2012):

$$
\mathrm{Q}=\left(\mathrm{m}_{2}-\mathrm{m}_{1}\right) / \mathrm{m}_{1}
$$

Where $\mathrm{Q}$ is the oil sorption capacity calculated as grams of oil per gram of sample while $\mathrm{m}_{1}$ and $\mathrm{m}_{2}$ are the weight of sample before and after oil absorption, respectively. 


\section{EXPERIMENTAL RESULTS}

\section{Sorption condition of different wastewater on raw kapok fiber (KF)}

The raw KF is very effective in removing the oily layer from the oily wastewater as shown in Figure 1 . This is due to the presence of a waxy hollow structure which makes it an excellent oil absorbent. After retrieval of the kapok fibers, oil slick on the water is barely visible. From the study, about $6.29 \mathrm{~g}$ of oil is fully removed from the wastewater with $1 \mathrm{~g}$ of kapok. The colour change of KF suggests the penetration and oil entrapment inside the hollow structure. Figure 1 (c) shows that oily-wastewater is being absorbed by the raw KF, while Figure 2 (c) shows that only a slight amount of emulsified wastewater is absorbed by the raw KF. On the other hand, non-oily wastewater is not being absorbed by raw KF as shown in Figure 3 (c). Furthermore, Figure 2 shows that the raw KF is partially immersed in the wastewater. The raw KF is not so effective in removing the oily substance from the emulsified wastewater. This may be due to the waxy surface of KF giving resistance to the water contented in the emulsion. Lastly, Figure 3 shows that the raw KF floated on the surface of the wastewater. The raw KF is not able to absorb the wastewater due to the waxy surface of raw KF that prevents water from sticking on the surface of KF. It is evident that the sorption condition of immiscible oil-and-liquid on raw KF is the best, follow by emulsified wastewater and non-oily wastewater.
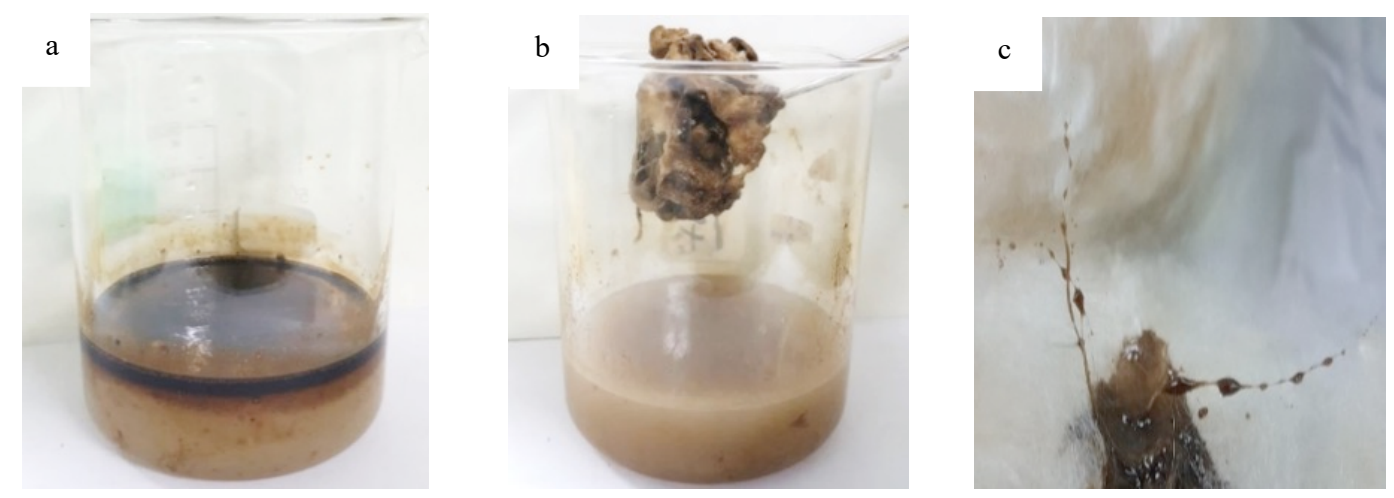

Figure 1. The condition of immiscible oil-and-liquid wastewater (a) before treatment, (b) after treatment and (c) oil droplet on raw KF.
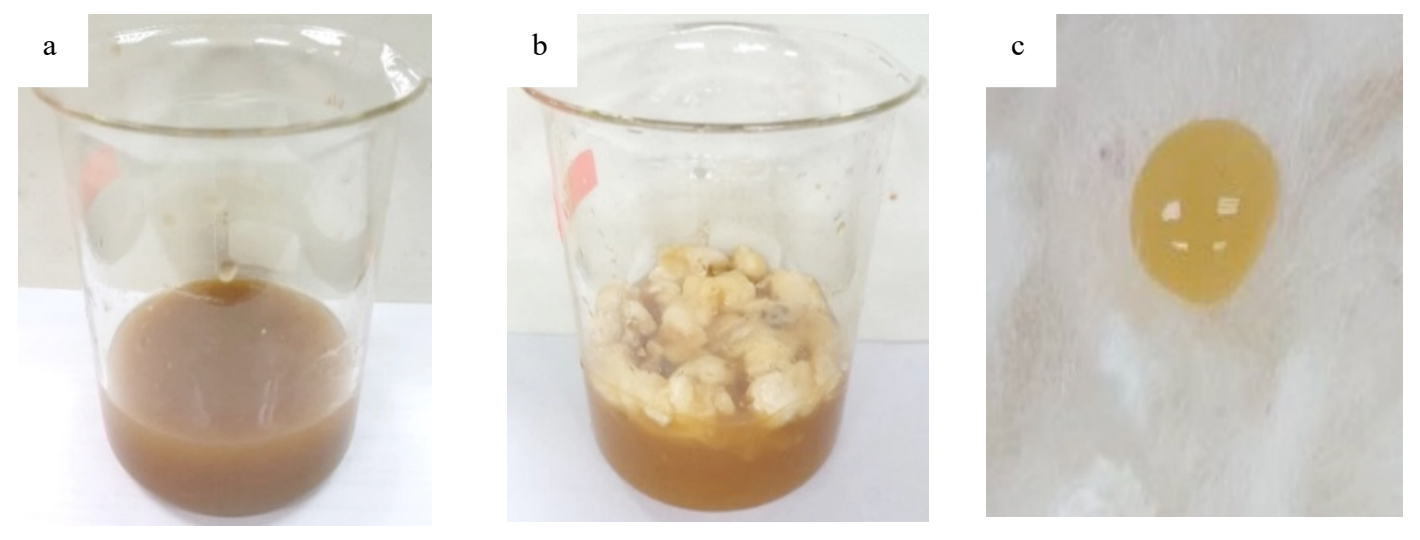

Figure 2. The condition of emulsified wastewater (a) before treatment, (b) after treatment and (c) emulsion droplet on raw KF. 

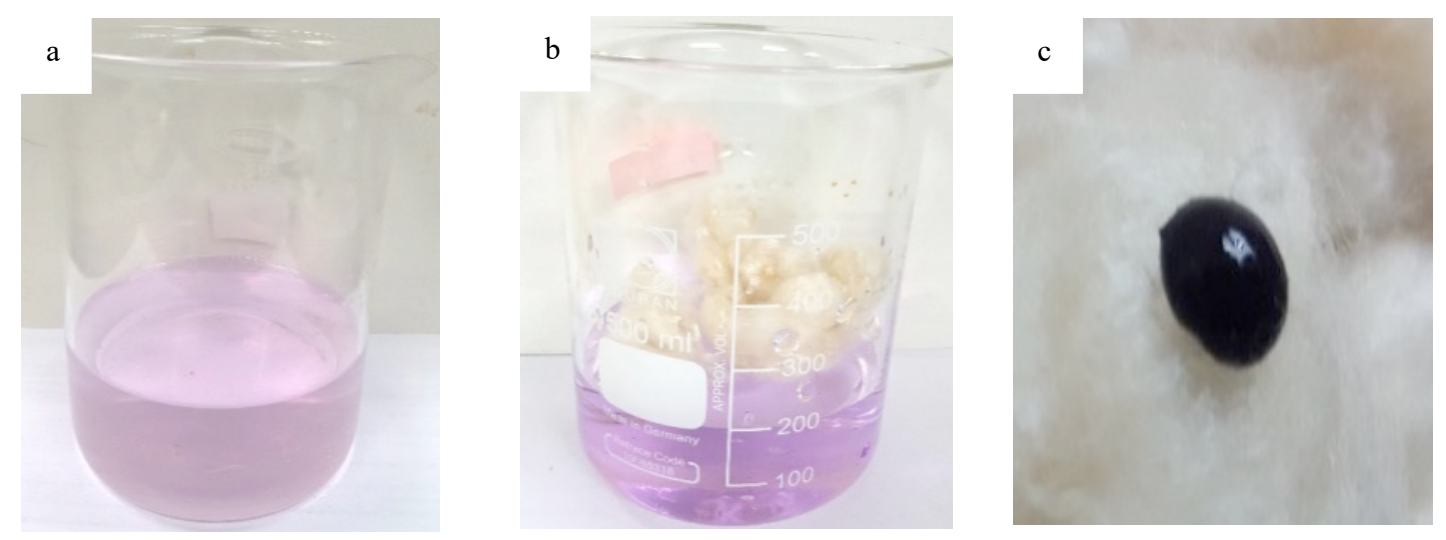

Figure 3. The condition of non-oily wastewater (a) before treatment, (b) after treatment and (c) water droplet on raw KF.

\section{FT-IR Spectra}

The infrared spectrum of kapok fiber is shown in Figure 4. For the raw kapok fiber, the following primary absorption peaks can be observed: the strong and broad peak at $3410 \mathrm{~cm}^{-1}$ was assigned to non-free $\mathrm{O}-\mathrm{H}$ stretching vibration, the strong peak around $2914 \mathrm{~cm}^{-1}$ was assigned to asymmetric and symmetric stretching vibration in $\mathrm{CH}_{2}$ and $\mathrm{CH}_{3}\left(\mathrm{Lim}_{\text {and }}\right.$ Huang, 2007), the absorption peak at $1740 \mathrm{~cm}^{-1}$ was due to $\mathrm{C}=\mathrm{O}$ stretching vibration of ketones, carboxylic groups and esters in lignin and acetyl ester groups in xylan (Matuana et al., 2001), the absorption bands at 1504 and $1602 \mathrm{~cm}^{-1}$ were attributed to aromatic ring carbon skeletal stretching, the bands around 1373 and $1245 \mathrm{~cm}^{-1}$ were within the range of C$\mathrm{H}$ and C-O bending vibration, respectively (Sun et al., 2003; Rodriguez-Cruz et al., 2008). By comparing the spectra of raw and treated kapok fiber, the following findings were obtained. The increase of absorption bands at $3410 \mathrm{~cm}^{-1} \mathrm{can} \mathrm{be}$ observed for both treated samples, implying the removal of plant wax from fiber surface and the increment of cellulose hydroxyl groups in fiber walls due to the breaking of hydrogen bond, and an intensive band at $2914 \mathrm{~cm}^{-1}$ is also concerned with the removal of surface wax (Lim and Huang, 2007b). For chloroform-treated sample, there is no obvious variation in other absorption bands except the change mentioned above. For ethanol-treated kapok, the bands around $1602 \mathrm{~cm}^{-1}$ and $1504 \mathrm{~cm}^{-1}$ nearly disappear, meaning that the bleaching actually leads to the cleavage of the aromatic ring in lignin (Sun et al., 2000).
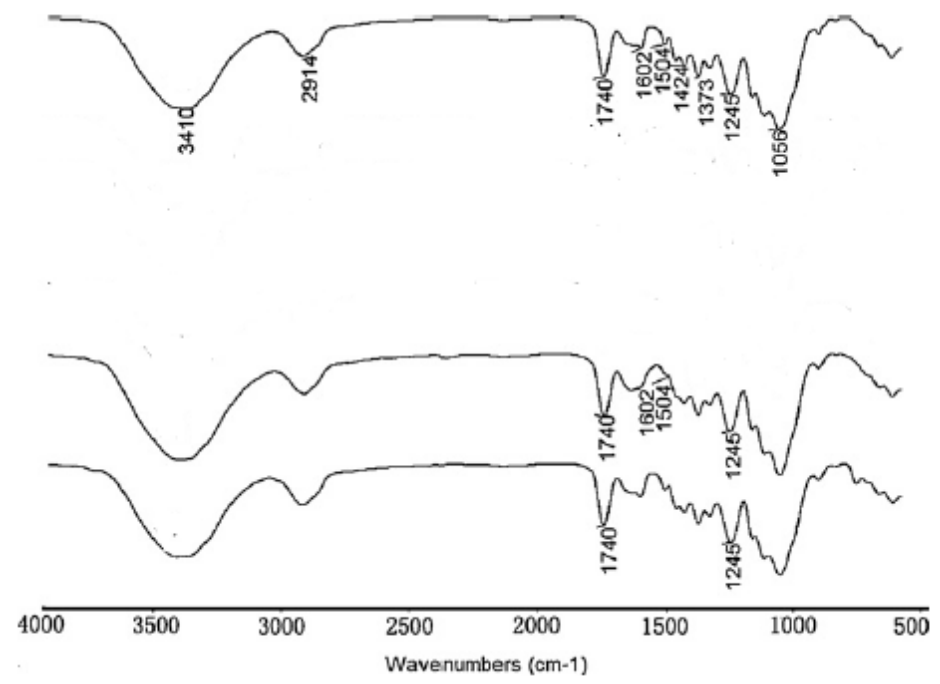

Figure 4. FTIR spectra of (a) raw, (b) ethanol-treated, (c) chloroform-treated kapok fiber.

\section{Morphology of kapok fiber (KF)}

Chloroform treatment and ethanol treatment were carried out to remove the raw kapok fibers' waxy surface. Figure 5 (a) illustrates the kapok fiber has a round shape and smooth surface. This network of hollow structures could have provided, not only ample interspatial area for oil to be retained and trapped within the kapok assembly as similarly being suggested for Milkweed floss (Choi and Moreau, 1993), but also the architecture for uniform distribution of absorbed oil within the kapok assembly. The presence of lumen structure has been considered as a contributing factor in the secure holding of oil after its collection (Abdullah et al.,2010). They may partly or fully replace air or water already present in 
the pores, within which fluids are held by capillary forces (Inagaki et al., 2002). In Figure 5 (c), the thin wall of ethanoltreated kapok fiber is well defined as compared to the treated KF in Figure 5 (d) that has a rougher surface. Figure 5 (c) and Figure 5 (d) also show that the treated KF will be flattened as the kapok fiber became pulp-like after pre-treatment with each solvent respectively. The overall tubular structure was retained unbroken. This result was similar to a previous report by other researchers (Abdullah et al., 2010). The air entrapment inside the kapok fiber disappeared after both solvent treatments (Figure 5 (c) and Figure 5 (d)). The structure became completely flattened with a flat ribbon-like shape. The surface of the kapok fibers were also rougher as compared with the untreated fibers. Visual examination of the solvent-treated kapok fibers found that they had lost their silky luster. It might be due to reduction in its surface wax after being treated with the solvents.
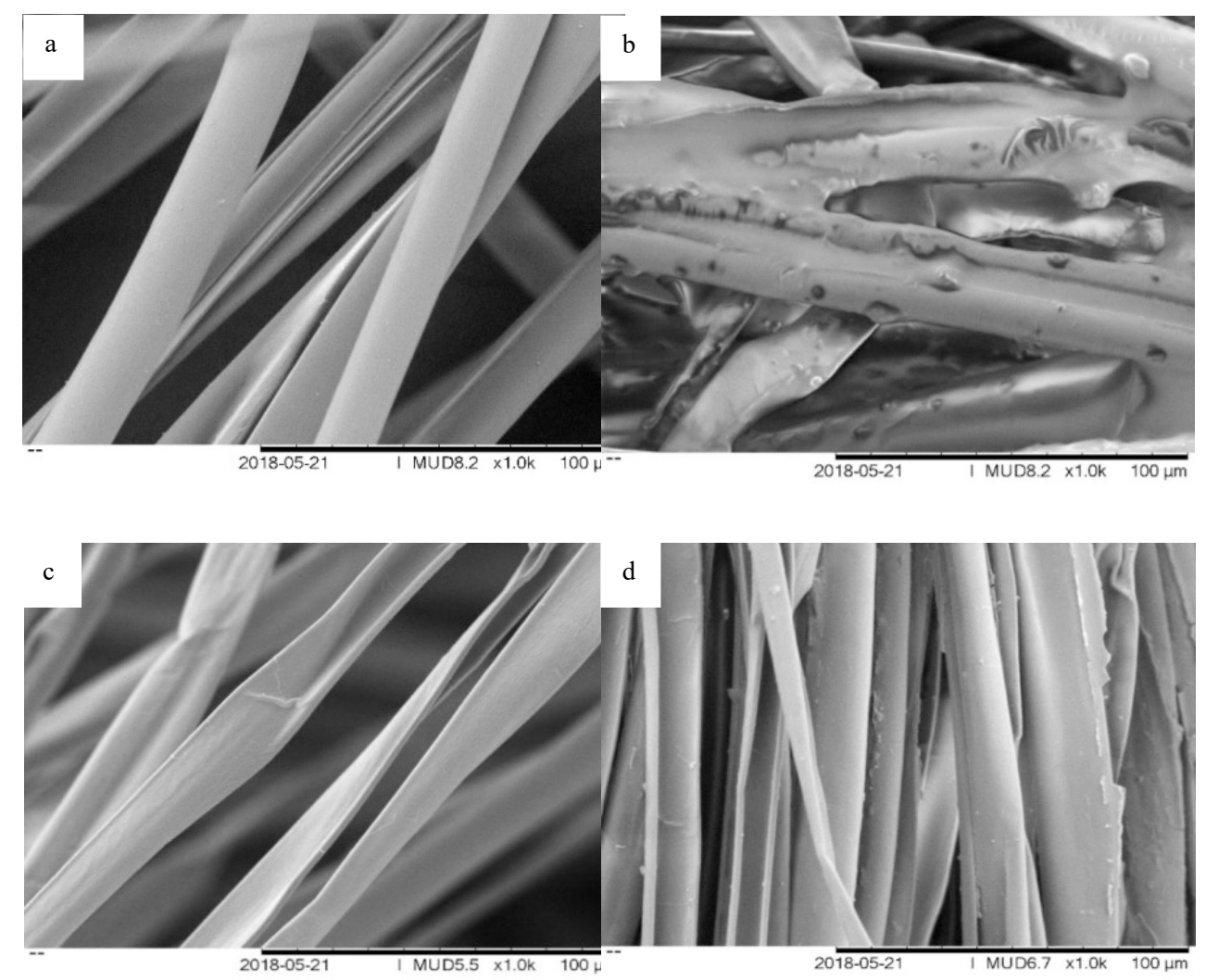

Figure 5. SEM micrograph of (a) raw KF, (b) raw KF after treated with oily wastewater, (c) ethanol-treated KF and (d) chloroform-treated $\mathrm{KF}$, with magnification at $1000 \mathrm{x}$.

\section{Sorption capacity of different kapok fiber (KF)}

Sorption capacity is the capacity of a physical and chemical process by which one substance becomes attached to another. The capacity of kapok to sorb and retain the absorbed oil during field application, transfer and handling operation are important parameters for sorbent evaluation.

Table 1 shows the net weight of adsorbate and oil sorption capacity of each kapok fiber (KF) on cooking oil. The net weight of adsorbate was obtained by using the weight of adsorbate after the adsorption minus the weight before adsorption. Then, the oil sorption capacity, Q is obtained using (1). Besides that, values from Table 1 are used to plot a bar chart as shown in Figure 6. From Figure 6, it shows that raw KF has the highest oil sorption capacity follow by ethanol-treated KF and chloroform-treated KF. This is probably because the effectiveness is resulted from the hydrophobic waxy coating on the kapok surface. Furthermore, there is also availability of penetrable lumen network with the inter-fiber pores located in the kapok microstructure that make raw KF to be effective as oil sorbent. The treated KF has lower sorption capacity as large amount of cellulosic content (hydroxyl group) present on the wall of kapok makes it less oleophilic (Zhang et al., 2016). Most of the hydrophilic hydroxyl groups in kapok fiber are exposed by the solvent, hence oil sorption ability is limited by these hydrophilic groups. The treated kapok fibers still retained their hydrophobicity/oleophilicity due to the incomplete wax removal. However, due to the change in the surface composition of the kapok fiber as a result of the solvent treatment, hence treated kapok fiber has lower sorption capacity than raw kapok fiber. 
Table 1. The net weight of adsorbate and oil sorption capacity of each kapok fiber (KF) on cooking oil.

\begin{tabular}{cccc}
\hline $\begin{array}{c}\text { Types of Kapok Fiber } \\
\text { (KF) }\end{array}$ & Raw Kapok Fiber & $\begin{array}{c}\text { Ethanol-treated Kapok } \\
\text { Fiber }\end{array}$ & $\begin{array}{c}\text { Chloroform-treated Kapok } \\
\text { Fiber }\end{array}$ \\
\hline $\begin{array}{c}\text { Net weight of adsorbate } \\
\text { (g) }\end{array}$ & 47.56 & 33.7 & 27.85 \\
\hline $\begin{array}{c}\text { Oil sorption capacity, Q } \\
(\mathbf{g} / \mathbf{g})\end{array}$ & 29.00 & 18.22 & 16.58 \\
\hline
\end{tabular}

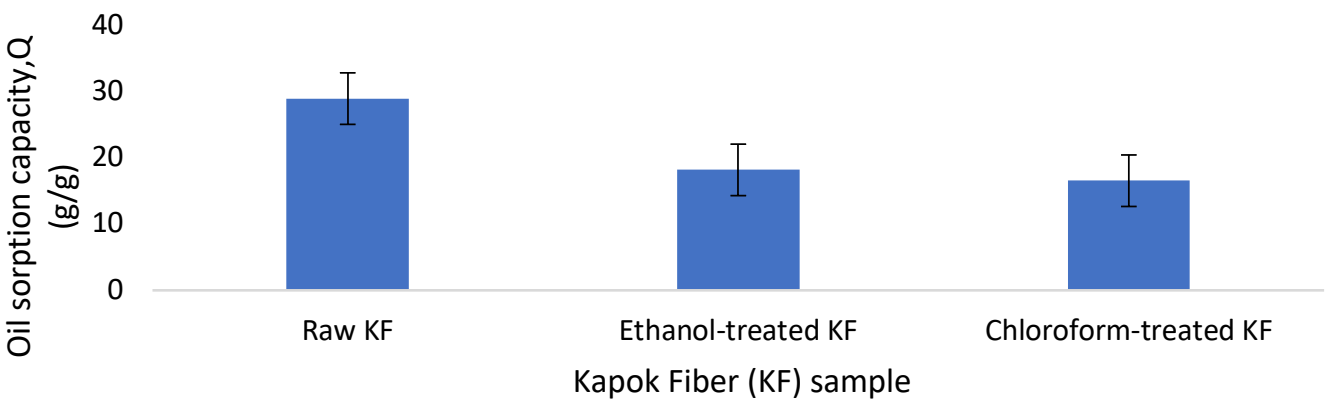

Figure 6. The oil sorption capacity of each kapok fiber (KF) on cooking oil.

Table 2 shows the net weight of adsorbate and sorption capacity of each kapok fiber (KF) on non-oily wastewater. The net weight of adsorbate is obtained by using the weight of adsorbate after the adsorption minus the weight before adsorption. Then, the sorption capacity, Q is calculated. Besides that, values from Table 2 are used to plot a bar chart as shown in Figure 7. From Figure 7, it shows that raw KF has the lowest sorption capacity follow by ethanol-treated KF and chloroform-treated KF. This is probably because the larger amount of cellulosic content (hydroxyl group) present on the wall of kapok makes it less hydrophobic (Zhang et al., 2016). Most of the hydrophilic hydroxyl groups in kapok fiber are exposed by the solvent, hence water sorption ability is higher by these hydrophilic groups. The treated kapok fibers still retained their hydrophobicity/oleophilicity due to the incomplete wax removal. However, due to the change in the surface composition of the kapok fiber as a result of the solvent treatment, hence treated kapok fiber has better sorption capacity then raw kapok fiber.

Table 2. The net weight of adsorbate and the sorption capacity of each Kapok Fiber (KF) on non-oily wastewater.

\begin{tabular}{cccc}
\hline $\begin{array}{c}\text { Types of Kapok Fiber } \\
\text { (KF) }\end{array}$ & Raw Kapok Fiber & $\begin{array}{c}\text { Ethanol-treated Kapok } \\
\text { Fiber }\end{array}$ & $\begin{array}{c}\text { Chloroform-treated Kapok } \\
\text { Fiber }\end{array}$ \\
\hline $\begin{array}{c}\text { Net weight of adsorbate } \\
\text { (g) }\end{array}$ & 1.00 & 6.31 & 6.21 \\
\hline $\begin{array}{c}\text { Sorption capacity, Q } \\
\text { (g/g) }\end{array}$ & 0.59 & 3.05 & 3.20 \\
\hline
\end{tabular}

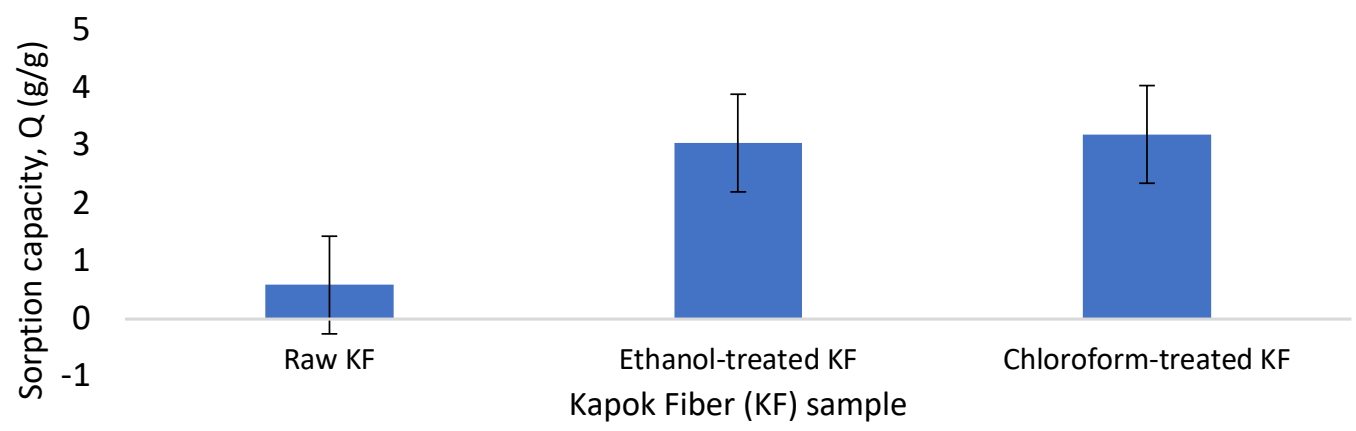

Figure 7. The sorption capacity of each kapok fiber (KF) on non-oily wastewater.

\section{CONCLUSION}

This study investigated the oil sorption capacity of raw, ethanol-treated and chloroform-treated kapok fiber on various types of wastewater. The variation of surface morphology, chemical compositions and functional group after different treatments were confirmed by FT-IR and SEM. In conclusion, the overall sorption characteristics of kapok shows that 
kapok is a potential lignocellulosic material for oil removal with high oil sorption. The result shows that raw KF has the best oil sorption capacity compared to the ethanol-treated KF and chloroform-treated KF. In addition, the fiber was capable of retaining most of oil sorption capacity after squeezing. High oil absorption, excellent reusability and good biodegradability make kapok fiber a suitable alternative to traditionally synthetic oil sorbents applied to the oil recovery in the absence of water. Lastly, kapok fiber has proven to be an effective oil adsorbent, thus pre-treatment of kapok fiber using other solvents to increase the adsorbency should be given more attention.

\section{ACKNOWLEDGMENT}

This work was financially supported by the Research and Innovation Department of Universiti Malaysia Pahang through the RDU 1703249 research grant.

\section{REFERENCES}

Abdullah, M. A., Rahmah, A. U., \& Man, Z. (2010). Physicochemical and sorption characteristics of Malaysian Ceiba pentandra L. Gaertn. as a natural oil sorbent, Journal of Hazardous Material, 177, 683-691.

Baseri, J. R., Palanisamy, P. N. \& Sivakumar, P. (2012). Comparative Studies of the Adsorption of Direct Dye on Activated Carbon and Conducting Polymer Composite. E-Journal of Chemistry, 9 (3), 1122-1134.

Bindu, S. P., Ray, D., Sengupta, S., Kar, T., Mohanty, A. \& Manju, M. (2011). Isolation of cellulose nanoparticles from sesame husk. Journal of Industrial \& Engineering Chemistry, 50, 871-876.

Choi, H., \& Moreau, J. P. (1993). Oil sorption behavior of various sorbents studied by sorption capacity measurement and environmental scanning electron microscopy. Microscopy Research and Technique, 25(5-6), 447-455.

Deschamps, G., Caruel, H., Borredon, M., Bonnin, C., \& Vignoles, C. (2003). Oil Removal from Water by Selective Sorption on Hydrophobic Cotton Fibers. 1. Study of Sorption Properties and Comparison with Other Cotton Fiber-Based Sorbents. Environmental Science \& Technology, 37(5), 1013-1015.

Fingas, M. (2000). The basics of oil spill cleanup (second ed.) New York, United State: Lewis.

Gao, J., Zhao, T. \& Chen, J.B. (2012). Composition, structure and property analysis of Calotropis gigantea, kapok and cotton fibers. Journal of Donghua University, 38 (2), 151-155.

Ge, D., Ru, X., Hong, S., Jiang, S., Tu, J., Wang, J., Zhang, A., Ji, S., Linkov, V., Ren, B., and Shi, W. (2010). Coating metals on cellulose-polypyrrole composites: A new route to self-powered drug delivery system, Journal of Electrochemistry Communications, 12, 1367-1370.

Guimarães, J. L., Frollini, E., da Silva, C. G., Wypych, F. \& Satyanarayana, K. G. (2009). Characterization of banana, sugarcane bagasse and sponge gourd fibers of Brazil. Industrial Crops Products-Journal, 30, 407-415.

Idris, J., Eyu, G. D., Mansor, A. M., Ahmad, Z., \& Chukwuekezie, C. S. (2014). A Preliminary Study of Biodegradable Waste as Sorbent Material for Oil-Spill Cleanup. The Scientific World Journal, 2014, 1-5.

Inagaki, M., Kawahara, A., Nishi, Y., and Iwashita, N. (2002). Heavy oil sorption and recovery by using carbon fiber felts, Carbon, 40, 1487-1492.

Lim, T.T., Huang, X.F., 2007b. Evaluation of hydrophobicity/oleophilicity of kapok and its performance in oily water filtration: comparison of raw and solvent-treated fibers. Ind. Crops Prod. 26, 125-134.

Matuana, L.M., Balatinecz, J.J., Sodhi, R.N.S., Park, C.B., 2001. Surface characterization of esterified cellulosic fibers by XPS and FTIR spectroscopy. Wood Sci. Technol. 35, 191-201.

Mwaikambo, L.Y., Ansell, M.P., 2002. Chemical modification of hemp, sisal, jute and kapok fibers by alkalization. J. Appl. Polym. Sci. 84, 2222-2234.

Mahadeva, S. K., Yun, S., and Kim, J. (2010). Flexible humidity and temperature sensor based on cellulose-polypyrrole nanocomposite, Journal of Sensors and Actuators A: Physical, 165(2), 194-199.

Panwar, N. L., Kaushik, S. C. \&Kothari, S. (2011). Role of renewable energy sources in environmental protection: A review. Renewable \& Sustainable Energy, 15, 1513-1524.

Pirani, S. \& Hashaikeh, R. (2012). Nanocrystalline cellulose extraction process and utilization of the byproduct for biofuels production. Journal of Carbohydrate Polymers. 93(1),357-363.

Rodriguez-Cruz, M.S., Aanrades, M.S., Parada, A.M., Sa 1nchez-marti in, M.J., 2008. Effect of different wood pretreatments on the sorption-desorption of linuron and metalaxyl by wood. J. Agric. Food Chem. 56, 7339-7346.

Rosa, M. F., Medeiros, E. S., Malmonge, J. A., Gregorski, K. S., Wood, D. F., Mattoso, L. H. C., Glenn, G., Orts, W. J. \& Imam, S.H. (2010). Cellulose nanowhiskers from coconut husk fibers: Effect of preparation conditions on their thermal and morphological behavior. Journal of Carbohydrate Polymers,81,83-92.

Sun, R.C., Fang, J.M., Tomkinson, J., 2000. Delignification of rye straw using hydrogen peroxide. Ind. Crops Prod. 12, 71-83.

Sun, X.F., Sun, R.C., Sun, J.X., 2003. A convenient acetylation of sugarcane bagasse using NBS as a catalyst for the preparation of oil sorption-active materials. J. Mater. Sci. 38, 3915-3923.

Varhegyi, G., Bobaly, B., Jakab, E. \& Chen, H. (2011). Thermogravimetric study of biomass pyrolysis kinetics. A distributed activation energy model with prediction tests. Energy Fuels, 25, 24-32.

Venkates, A.\& Rao, W. (2006). Adsorption and desorption of Organic liquids in elastic superhydrrophobic silica aerogels. Journal of Colloid Interface Sciences, 305, 124-132.

Wang, J., Zheng, Y., \& Wang, A. (2012). Effect of kapok fiber treated with various solvents on oil absorbency. Industrial Crops and Products, 40, 178-184.

Zhang, X., Wang, C., Chai, W., Liu, X., Xu, Y., \& Zhou, S. (2016). Kapok fiber as a natural source for fabrication of oil absorbent. Journal of Chemical Technology \& Biotechnology, 92(7), 1613-1619.

Zheng, Y., Wang, J., Zhu, Y., \& Wang, A. (2015). Research and application of kapok fiber as an absorbing material: A mini review. Journal of Environmental Sciences, 27, 21-32. 